\title{
Application of a Device in Times of Pandemic: Safety for the Patient and Medical Personnel
}

\author{
Niño MC*, Pauwels A, Raffan F, Arango E and López JP \\ Department of Anesthesiology, Hospital Universitario Fundación Santa Fe de Bogotá, Bogotá, Colombia \\ *Corresponding author: Maria Claudia Niño, Department of Anesthesiology, Hospital Universitario Fundación Santa Fe de Bogotá, Bogotá, Colombia
}

Received: May 14, 2021; Accepted: May 21, 2021; Published: May 28, 2021

\section{Introduction}

In Colombia, 500,000 COVID-19 cases and 15,800 deaths have been reported, among which health personnel cases and deaths amount to 5,619, and 43 respectively [1]. Age is an independent risk factor for suffering from a severe disease, with the ages of 65 and over representing the highest risk. In the US, individuals over the age of 65 represent $45 \%$ of hospital admissions, 53\% of intensive care unit admissions, and $80 \%$ of fatalities [2]. In Colombia, the installed capacity of beds in the ICU for the care of COVID-19 increased by $36 \%$, most of them in mechanical ventilation. The increase in life expectancy and the decrease in the birth rate have led to a significant increase in the average age of the population, where probably a third of geriatric patients will undergo a surgical procedure [3]. From the anesthetic point of view, this has implications in airway management due to an increase in the difficulty of positive pressure ventilation.

On the other hand, the highest viral load of SARS-CoV-2 has been reported in sputum and secretions of the upper respiratory tract, especially nasal [4]. However, tracheal intubation is considered a high-risk procedure for health personnel due to the risk of exposure by aerosolization [5]. For this reason, in airway management, the most experienced professional should be chosen, simulation exercises of personal protective equipment protocols implemented, adequate spaces to manage the airway allocated, airway management equipment for patients diagnosed with or suspected of having COVID-19 made available, necessary or potentially necessary medications guaranteed, airway management guidelines in times of pandemic developed further, and the situations that lead to potential aerosolization avoided or reduced.

\section{Device Description}

In 2017, the authors first published the description of a new device for the ventilation of edentulous patients called NIPARA, (NI) Niño, (PA) Pauwels, (R) Raffan, and (A) Arango, demonstrating a significant improvement in the coupling of the face mask by an increase in positive pressure ventilation and a decrease in the loss of escape volume between the mask and the patient, which in theory reduces the potential aerosolization of this intervention.

The device consists of an intraoral extended U-shaped plastic plate, latex-free plastic materials (4.6 inches x 1.4 inches) with right and left side extensions. In the midline, it has a mating surface on both the top and bottom that engages the labial frenulum allowing intraoral retention, and the lateral extensions are placed between the gums and cheeks. The device is inserted using the same insertion technique as conventional oropharyngeal cannulas inserted into the device's central hole. Once the NIPARA is inserted, the face mask is used as usual by resting it on the patient's face for manual positive pressure ventilation before the intubation of the patient (Figure 1) [6].

\section{Discussion}

Ventilation with a face mask is a procedure that produces a high degree of aerosolization, and all the strategies that decrease it, such as two-hand ventilation and two operators providing an adequate seal to the face or rapid sequence induction, are indicated in the time of induction of anesthesia. Assessment of the airway's difficulty in Covid-19 patients can be carried out with the MACOCHA scale before the procedures [7].

This article mainly focuses on the face mask ventilation maneuver in the emergency, resuscitation, surgery, or intensive care setting, where patient and staff protection is essential. Therefore, according to the principles of the Safe Airway Society for the management of the airways and endotracheal intubation for the group of adult patients with COVID-19, it is crucial to follow the rapid sequence intubation protocol, to decrease long periods of high-flow oxygenation or noninvasive ventilation because of its potential aerosol generation. Due to the proximity of the medical staff to the patient's airway, it is essential to minimize the risk of aerosolization generation with these procedures [8]. Among the predictors of difficult ventilation are edentulous patients, since it is difficult to obtain an adequate seal between the mask and the patient's face due to the loss of vertical dimension, allowing air leakage [9].

In the first semester of 2020, during the Covid-19 Pandemic, 4,951 patients have been operated on at Foundation Santa Fe de Bogotá University Hospital, Bogotá, Colombia.

Near to $27 \%$ were (a group of 1,347 patients) over 60 years of age, for which the possibility of being edentulous according to the National Study of Oral Health of Colombia is approximately 33\% which is probably equivalent to 440 patients that required some support of the airway and surely to be ventilated with the safety protocols. Thus, by restoring the vertical facial dimension of edentulous patients with NIPARA, a better adaptation of the facial mask is achieved and lower resistance to ventilation, thus reducing the possibility of particle aerosolization (Figure 2) [10]. 


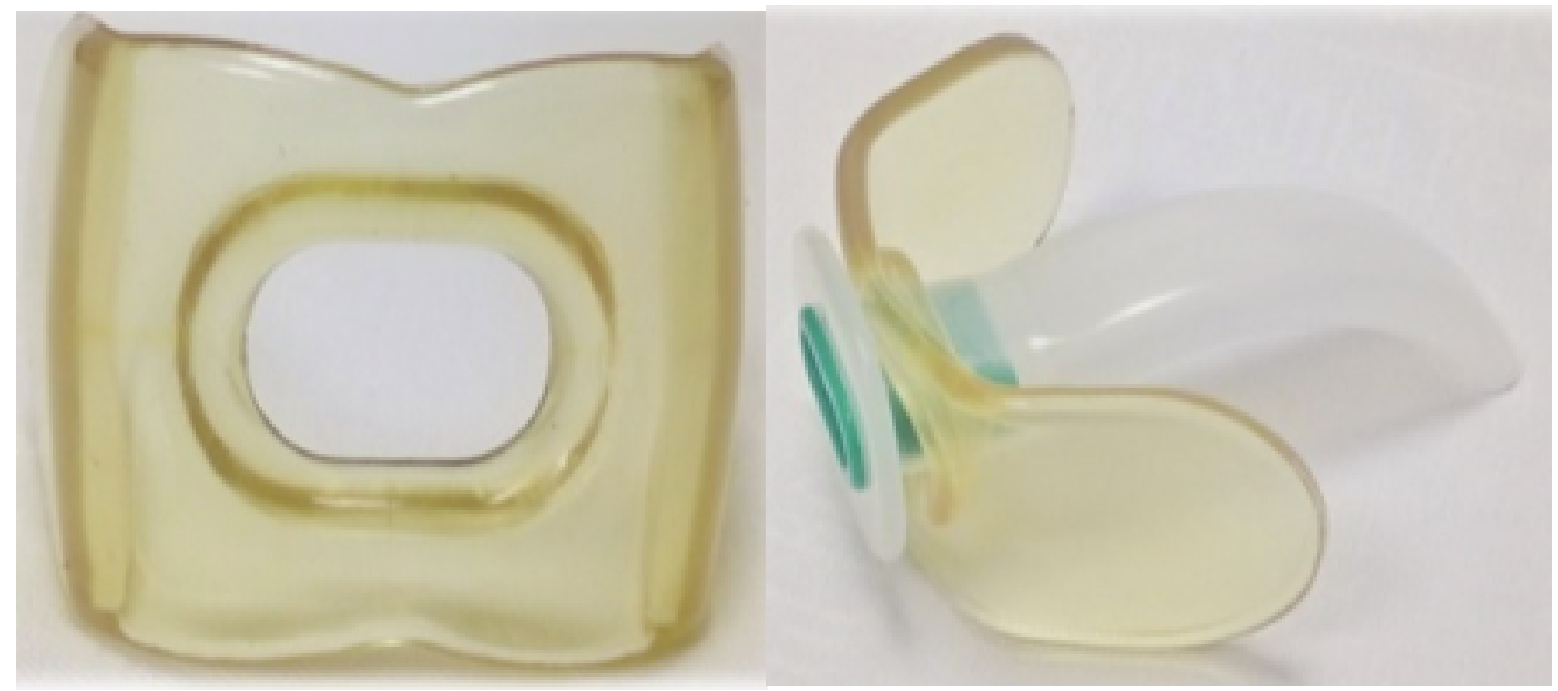

Figure 1: NIPARA device.

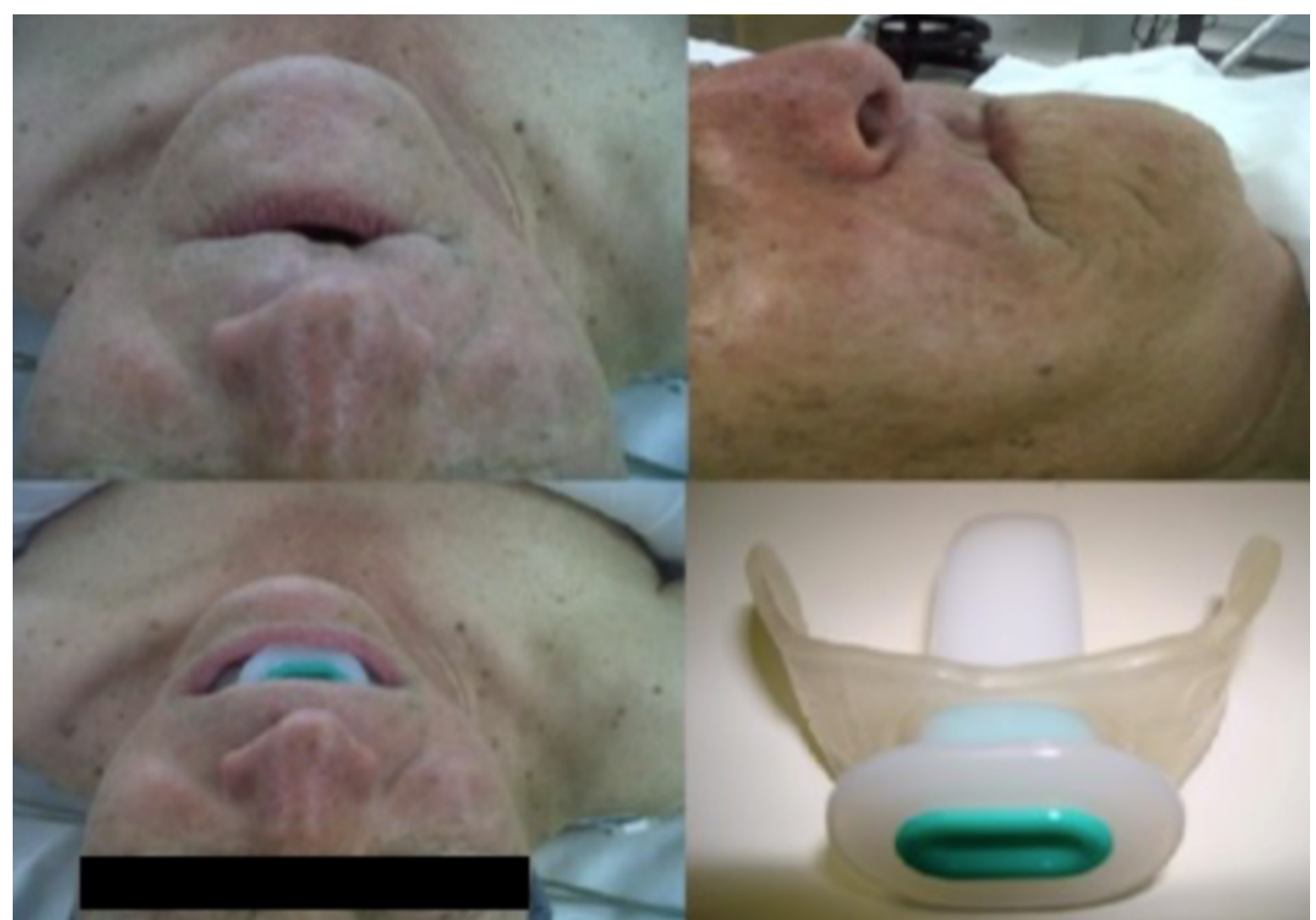

Figure 2: A patient using and not using NIPARA before ventilation.

\section{Conclusion}

This article does not intend to change the safety protocols already established or indicate mask ventilation in all patients. However, if necessary, the NIPARA can be a low-cost device, a useful, easy-touse, and safe tool taking into account that the population older than 65 represents a high percentage of patients who go to hospitals and require ventilation either in endoscopy procedures, surgery, intensive care unit or in an emergency room. Additionally, they present total edentulism, making it difficult to seal between the marking and the patient's face, generating an aerosol outlet with a high risk of contamination.

\section{References}

1. https://covid19.minsalud.gov.co/

2. Enfermedad de Coronavirus 2019 (Covid-19). BMJ. Best Practice, Agosto 10, 2020. 
3. Nazar C, Zamora HM, Fuentes HR, Lema FG (2015) Paciente adulto mayor y cirugía no cardíaca: ¿qué debemos saber? Rev Chil Cir 67: 309-317.

4. Wang W, Xu Y, Gao R, Lu R, Han K, et al. (2020) Detection of SARS-CoV-2 in Different Types of Clinical Specimens. JAMA 323: 1843-1844. [crossref]

5. Wu Z, McGoogan JM (2020) Characteristics of and Important Lessons from the Coronavirus Disease 2019 (COVID-19) Outbreak in China: Summary of a Report of 72314 Cases from the Chinese Center for Disease Control and Prevention. JAMA 323: 1239-1242. [crossref]

6. Niño MC, Pauwels A, Raffan F, Arango E, Romero DJ, et al. (2017) Efficacy of a new device to optimize positive pressure ventilation via face mask in edentulous patients: a randomized trial. Expert Rev Med Devices 14: 315-320. [crossref]
7. Joint statement: Supporting doctors in the event of a Covid-19 epidemic in the UK 2020. Chief Medical Officers of Wales, Scotland, Northern Ireland, England, National Medical Director NHSE/I, General Medical Council.

8. Brewster DJ, Chrimes N, Do TB, Fraser K, Groombridge CJ, et al. (2020) Consensus statement: Safe Airway Society principles of airway management and tracheal intubation specific to the COVID-19 adult patient group. Med J Aust 212: 472-481. [crossref]

9. Racine SX, Solis A, Hamou NA, Letoumelin P, Hepner DL, et al. (2010) Face mask ventilation in edentulous patients: a comparison of mandibular groove and lower lip placement. Anesthesiology 112: 1190-1193. [crossref]

10. Estudio Nacional de Salud Bucal IV, Ministerio de Salud y Protección Social 2013-2014.

Niño MC, Pauwels A, Raffan F, Arango E, López JP (2021) Application of a Device in Times of Pandemic: Safety for the Patient and Medical Personnel. Integr J Anesth Sur Volume 2(2): 1-3. 